\title{
The Arctic and Antarctic Sea-Ice Area Index Records versus Measured and Modeled Temperature Data
}

\author{
Nicola Scafetta and Adriano Mazzarella \\ Meteorological Observatory, Department of Earth Sciences, Environment and Georesources, University of Naples Federico II, \\ Largo S. Marcellino 10, 80138 Naples, Italy
}

Correspondence should be addressed to Nicola Scafetta; nicola.scafetta@unina.it

Received 12 March 2015; Revised 6 July 2015; Accepted 8 July 2015

Academic Editor: Luis Gimeno

Copyright (C) 2015 N. Scafetta and A. Mazzarella. This is an open access article distributed under the Creative Commons Attribution License, which permits unrestricted use, distribution, and reproduction in any medium, provided the original work is properly cited.

Here we study the Arctic and Antarctic sea-ice area records provided by the National Snow and Ice Data Center (NSIDC). These records reveal an opposite climatic behavior: since 1978 the Arctic sea-ice area index decreased, that is, the region has warmed, while the Antarctic sea-ice area index increased, that is, the region has cooled. During the last 7 years the Arctic sea-ice area has stabilized while the Antarctic sea-ice area has increased at a rate significantly higher than during the previous decades; that is, the sea-ice area of both regions has experienced a positive acceleration. This result is quite robust because it is confirmed by alternative temperature climate indices of the same regions. We also found that a significant 4-5-year natural oscillation characterizes the climate of these sea-ice polar areas. On the contrary, we found that the CMIP5 general circulation models have predicted significant warming in both polar sea regions and failed to reproduce the strong 4-5-year oscillation. Because the CMIP5 GCM simulations are inconsistent with the observations, we suggest that important natural mechanisms of climate change are missing in the models.

\section{Introduction}

Sea-ice is frozen seawater. It covers about 7\% of the Earth's surface and about $12 \%$ of the world's oceans [1]. Sea-ice forms mostly in the Earth's polar regions, that is, in the Arctic ocean and in the sea-area around Antarctica. Sea-ice has a temperature very close to the melting point. Its evolution is measured mostly by ice mass balance compared to standard instruments. Because of its thermodynamic properties, seaice extent and area strongly depend on the variation of the local albedo, on the fluctuations of the temperature, on the circulation of the ocean, and on the variation of the air current.

Changes in the net radiation balance regulating the global climate are amplified near the poles relative to the planetary average (e.g., [2]). In fact, the Earth is characterized by a circulating atmosphere and ocean that convect heat polewards. The albedo feedback is also the greatest at the poles given the appearance and disappearance of white sea-ice against dark-blue seawater. These physical properties make the poles very sensitive to global climatic changes [3]. Thus, through the magnifying lens of the polar amplification effect, time series of sea-ice area are quite important indices to study climate changes regarding both the polar regions and the global climate.

NASA [4] found rapid changes in the Earth's polar ice sheets that have been of great concern for many observers. In fact, melting of the land-based polar glaciers could drastically change the worldwide sea levels by several meters. The melting of small glaciers and polar ice caps on the margins of Greenland and the Antarctic Peninsula should increase sea level by about $0.5 \mathrm{~m}$, while, if the entire Greenland or Antarctic Ice Sheet melts, sea level could rise about $7.2 \mathrm{~m}$ and $61.1 \mathrm{~m}$, respectively (cf. [5]). The collapse of the West Antarctic Ice Sheet could raise sea level by at least $3.3 \mathrm{~m}[6,7]$. Even a small rise in sea level could affect a significant percentage of the world's population, and it could significantly impact major cities like New York city.

Information on the thickness and movements of the polar ice caps is collected through radar, microwave, and laser instruments mounted on a number of orbiting satellites. The detailed and frequent observations provided by 
the space-based tools permit the monitoring of the changes in the ice caps to a degree that was not possible by previous land-ocean based methods $[8,9]$.

Various coupled factors control sea-ice. The warming climate reduces the areal extent of ice in the polar regions. This will decrease the albedo, that is, the tendency to reflect incoming solar radiation, of the polar regions. White ice reflects much of the sunlight that reaches it and this has a cooling effect on the overall climate. With a decreased albedo, the climate warms activating a strong feedback. However, the melting ice could also impact the thermohaline circulation of the oceans and could paradoxically cause cooling [10]. Ironically, it has been argued that global warming could also delay or offset the effects of the coming ice age [11]. These seemingly contradictory results can only be resolved through detailed scientific observation and careful data analysis. The process of global warming and other forces of climate change will continue to be reflected in the ice caps.

While the Arctic has been warming, there is currently an Antarctica cooling controversy that needs to be addressed and possibly solved (http://en.wikipedia.org/wiki/Antarctica cooling_controversy). In fact, while it has been established that the Antarctic Peninsula in the West Antarctica has been warming (e.g., [12]), trends elsewhere on the continent, in particular in the East Antarctica, are more uncertain and have also shown cooling over various decades (e.g., [13]).

This issue is important for the climate change debate. In fact, the global warming observed since the 1970s has been typically associated with anthropogenic greenhouse gas emissions [14]. Global warming should cause melting of the glaciers and of the polar ice sheets. Understanding whether the current general circulation models are able to properly predict observed continental climatic changes is fundamental to determine whether natural mechanisms not discovered, understood, or modeled yet are present in the climate system (cf. [15]).

This paper aims to study in detail the polar sea-ice area index records, compare the observed interannual and decadal patterns among several alternative climatic temperature records of the same regions, and test whether the Coupled Model Intercomparison Project Phase 5 general circulation models (CMIP5 GCMs) [14] predict the observed pattern.

\section{Data}

Herein we use the monthly resolved Arctic and Antarctic seaice area index records downloaded from Climate Explorer (http://climexp.knmi.nl) provided by the National Snow and Ice Data Center (NSIDC) (http://nsidc.org/data/g02135) [8]. Data values are in millions of square kilometers and cover the period from November 1978 to January 2015. Two values were missing (December 1987 and January 1988) that were filled using linear interpolation. Figure 1 shows example maps of average sea-ice extent in the Arctic summer (September) and winter (March) and in the Antarctic summer (February) and winter (September).

Figures 2(a) and 2(b) show the Arctic and Antarctic sea-ice area index records, respectively. The annual seasonal oscillation is evident in both records. The two records present a 6-month time-lag in their annual oscillation because, as is well known, the Northern and Southern hemispheres have inverted seasonal temperature.

To better compare the two records, we use a 12 -month moving average algorithm to separate the annual from the interannual scales. Figure 3 shows the 12-month moving average smoothed records.

The annual smooth record of the Arctic sea-ice area has decreased from about $10.5 \cdot 10^{6} \mathrm{~km}^{2}$ in 1978 to about 9 . $10^{6} \mathrm{~km}^{2}$ in 2014 with a linear rate of $-0.049 \pm 0.001 \mathrm{~km}^{2} /$ year. Since 2007 the record has been more stable with a linear rate of $-0.012 \pm 0.009 \mathrm{~km}^{2} /$ year. On the contrary, the annual smooth record of the Antarctic sea-ice area has increased from about $8.5 \cdot 10^{6} \mathrm{~km}^{2}$ in 1978 to about $9.5 \cdot 10^{6} \mathrm{~km}^{2}$ in 2014 with a linear rate of $0.020 \pm 0.001 \mathrm{~km}^{2} /$ year. Since 2007 the rate increased to $0.077 \pm 0.013 \mathrm{~km}^{2} /$ year. Therefore, both indices have experienced positive accelerations during the last decade. In general, the two records are negatively correlated on the analyzed multidecadal scale: the correlation coefficient is $r=-0.56$. Significant oscillations of about 45 years are also observed in both records, in particular in Antarctica.

Figure 4 compares the annual oscillation of the Arctic and Antarctic sea-ice area indices obtained by detrending the original records depicted in Figure 2 of their 12-month smooth average curve depicted in Figure 3. It is observed that: (1) the expected seasonal inversion exists between the Northern and Southern hemispheres; (2) the amplitude of the Arctic annual oscillation is always smaller than the amplitude of the Antarctic annual oscillation; (3) the amplitude of the annual oscillation varies in time.

The latter property can be highlighted by estimating the time-dependent amplitude of the annual oscillation. We estimate the standard deviation function of the annual oscillation depicted in Figure 4 and multiply it by $2 \sqrt{2}$. Note that, given a sinusoidal function $f(t)=(1 / 2) A \sin (2 \pi t)$, its (min-to-max) amplitude $A$ is $2 \sqrt{2}$ times the standard deviation of $f(t)$ on the period of 1 oscillation. The two timedependent amplitude records are depicted in Figure 5.

Figure 5 shows that the amplitude of the annual cycle for the Arctic sea-ice area index records has increased from about $9 \cdot 10^{6} \mathrm{~km}^{2}$ in 1978 to about $10.5 \cdot 10^{6} \mathrm{~km}^{2}$ in 2014 . On the contrary, the amplitude of the annual cycle for the Antarctic sea-ice area index records has been quire stationary between $13 \cdot 10^{6}$ and $14 \cdot 10^{6} \mathrm{~km}^{2}$ during the $1978-2014$ period. Figure 5 also highlights the existence of a quasi 4-5year oscillation in the Arctic and Antarctic smooth records although this oscillation is more regular in the latter. After 2000 the two records appear to have their 4-5-year oscillation negatively correlated: when the Arctic presents a larger annual oscillation, the Antarctic presents a smaller annual oscillation, and vice versa. However, this pattern does not appear to hold for the entire 1978-2014 period where the correlation is only weakly negative: $r=-0.05$.

Figures 6(a) (Arctic) and 6(b) (Antarctic) compare the 12-month moving average record (Figure 3 ) and the annual amplitude record (Figure 5) of the sea-ice area indices, 

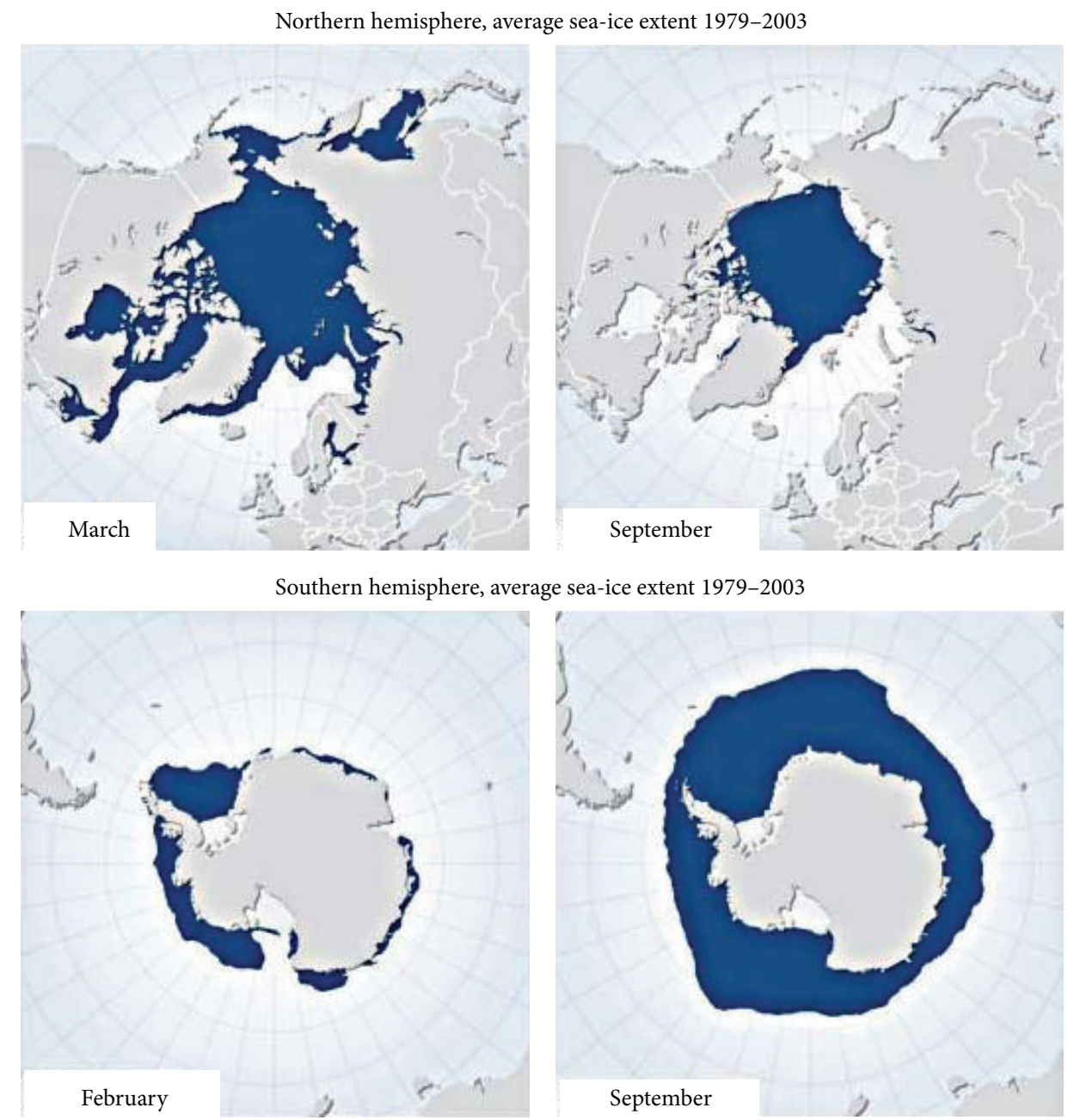

Figure 1: Example maps of average sea-ice extent in the Arctic summer (September) and winter (March), and in the Antarctic summer (February) and winter (September). Adapted from J. Stroeve and W. Meier (1999, updated 2005). (Sea Ice Trends and Climatologies from SMMR and SSM/I. Boulder, Colorado, USA. National Snow and Ice Data Center.)

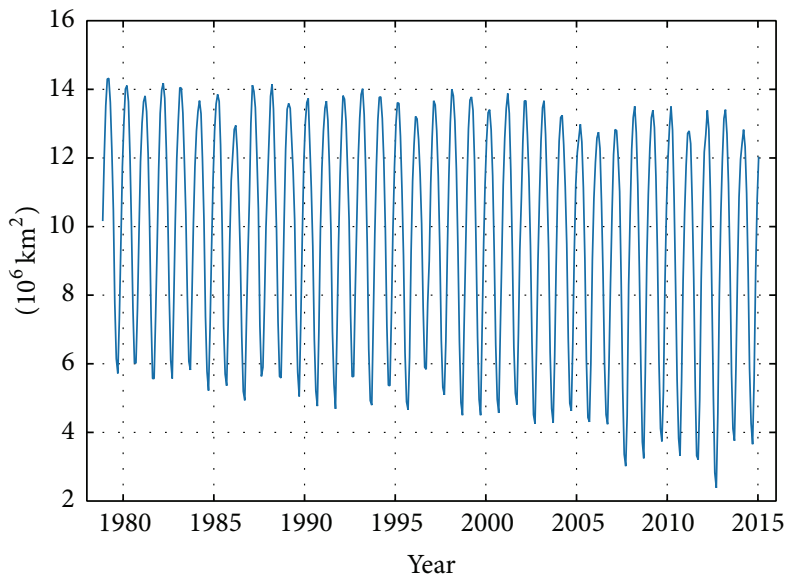

— North ice area

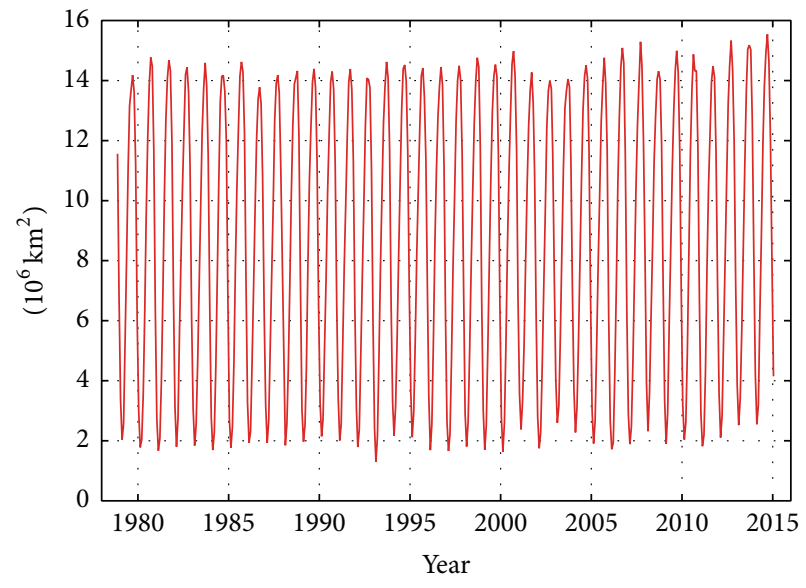

— South ice area

(a)

Figure 2: (a) The Arctic and (b) Antarctic sea-ice area indices [8]. 


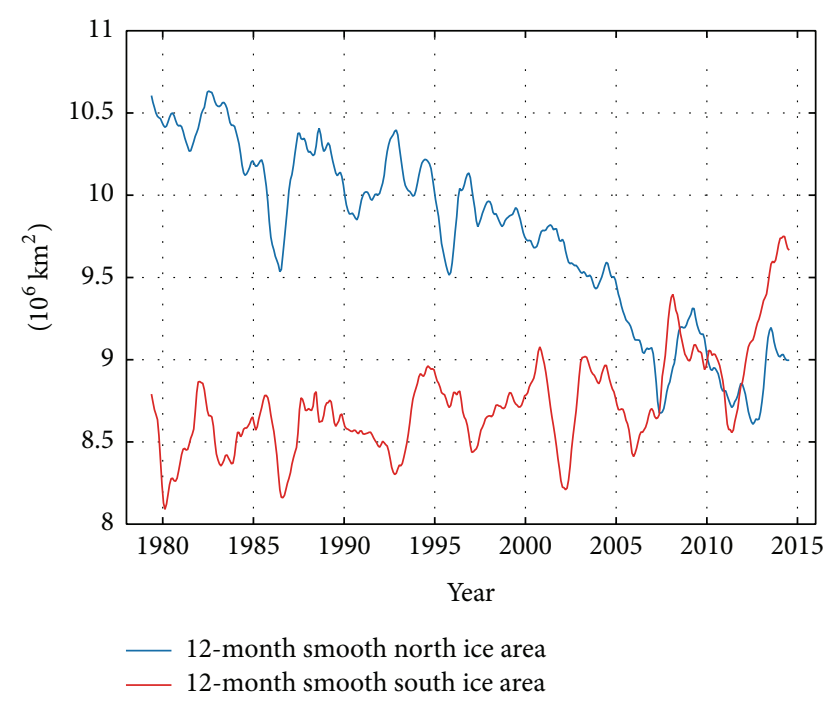

Figure 3: Comparison between 12-month moving average of the Arctic and Antarctic sea-ice area index records.

respectively. Figure 6(a) shows that for the Arctic the annual amplitude is negatively correlated with the multidecadal trending, $r=-0.79$; as the annual mean sea-ice area decreases the annual amplitude increases. Figure 6(b) shows that for Antarctica there exists a weak negative correlation between the annual mean record and the annual amplitude record: $r=-0.09$. Figure 6(b) shows that for Antarctica the annual mean record and the annual amplitude record present the 4-5-year oscillations that are negatively correlated with each other.

\section{Comparison versus Climate Indices and Model Predictions}

The Arctic and Antarctic sea-ice area index records reveal interesting patterns, multiscaling coupling, and teleconnections. In addition to the well-expected seasonal inversion, the two records are negatively correlated on the multidecadal scale. In the Arctic, the mean annual sea-ice area decreased from 1978 to 2014, while in Antarctica it increased.

This finding is important because the interannual trending of the sea-ice area should be negatively correlated with the climatic temperature changes of the involved regions. To test this claim we use alternative climate indices downloaded from Climate Explorer (http://climexp.knmi.nl).

The HadCRUT4 instrumental surface temperature database [16] is used to estimate the temperature of the polar regions: $[65 \mathrm{~N}: 90 \mathrm{~N}]$ for the Arctic and $[-75 \mathrm{~N}:-60 \mathrm{~N}]$ for the Antarctic sea areas. Because the data are sporadic, we required a minimal fraction of $25 \%$ of valid points from 1978 to 2014. Figure 7(a) shows that, as expected, the Arctic warmed from 1978 to 2014 and this trend $\left(+5.4 \pm 0.2^{\circ} \mathrm{C}\right.$ per century) is negatively correlated with the Arctic sea-ice area index: $r=-0.90$. For Antarctica the temperature record is more sporadic because often only 5 months of data per year are available due to the fact that ships could navigate the area

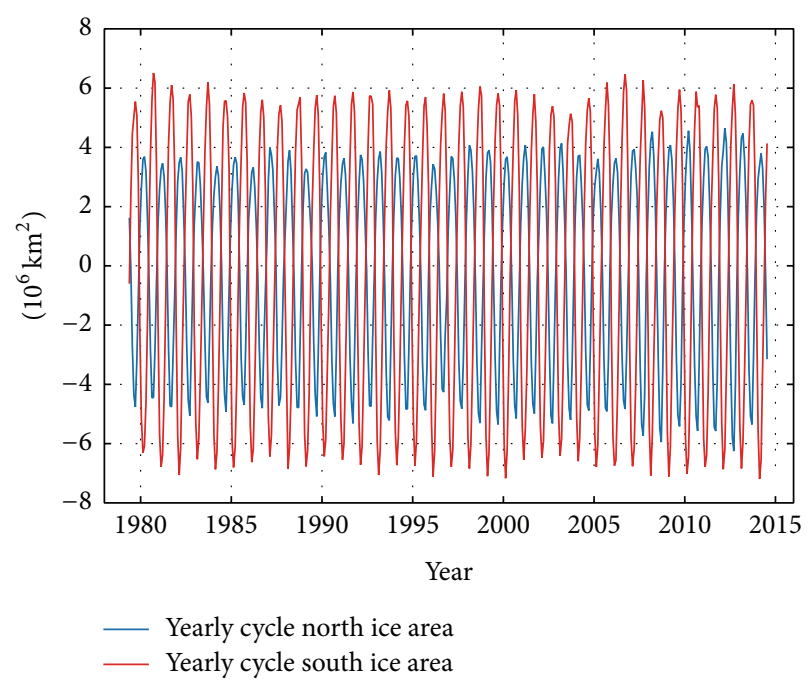

FIgure 4: Annual oscillation of the Arctic and Antarctic sea-ice area index records.

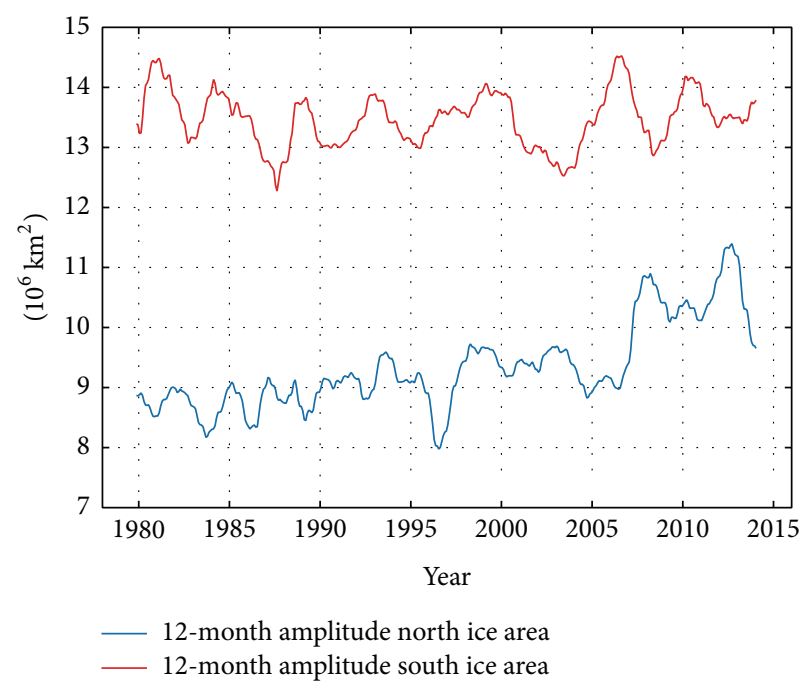

FIgUre 5: Amplitude of the annual oscillation depicted in Figure 4 of the Arctic and Antarctic sea-ice area indices.

only during the warmest months of the year when the sea is ice-free. Figure 7(b) shows that the Antarctic sea region slightly cooled from 1978 to 2014 at a rate of $-0.5 \pm 0.17^{\circ} \mathrm{C}$ per century and that, as expected, this trend is negatively correlated with the Antarctic sea-ice area index: $r=-0.28$.

A similar result is obtained using the vertical ocean mean temperature (depth $0-100 \mathrm{~m}$ ) anomaly provided by the National Oceanographic Data Center (NODC). Figures 8(a) and 8 (b) compare the NODC temperature with the sea-ice area in the Arctic and Antarctic, respectively. In both cases a strong negative correlation is observed: Arctic, $r=-0.85$; Antarctica, $r=-0.82$.

Finally we compare these results against the temperature predictions of the general circulation models used in the Fifth Assessment Report, Climate Change 2013, of the IPCC (http://www.ipcc.ch/report/ar5/wg1/). We use annual 


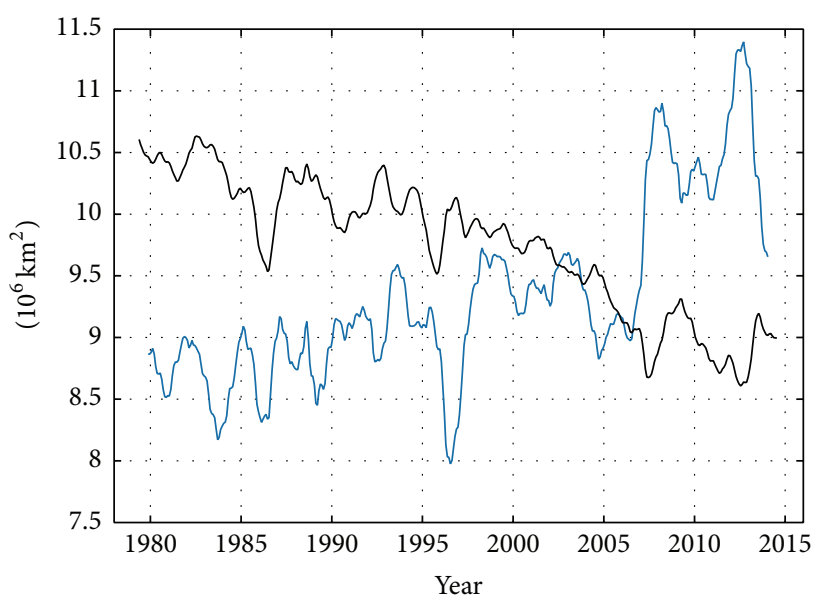

— 12-month amplitude north ice area

- 12-month smooth north ice area

(a)

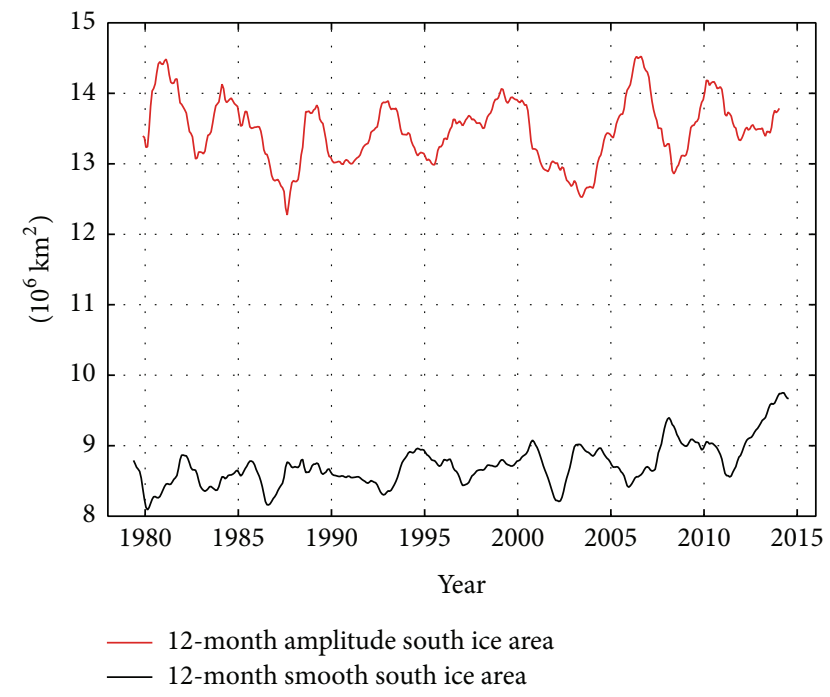

(b)

Figure 6: (a) The Arctic and (b) Antarctica. Comparison between the 12-month moving average record (Figure 3) and the annual amplitude record (Figure 5) of the sea-ice area indices.

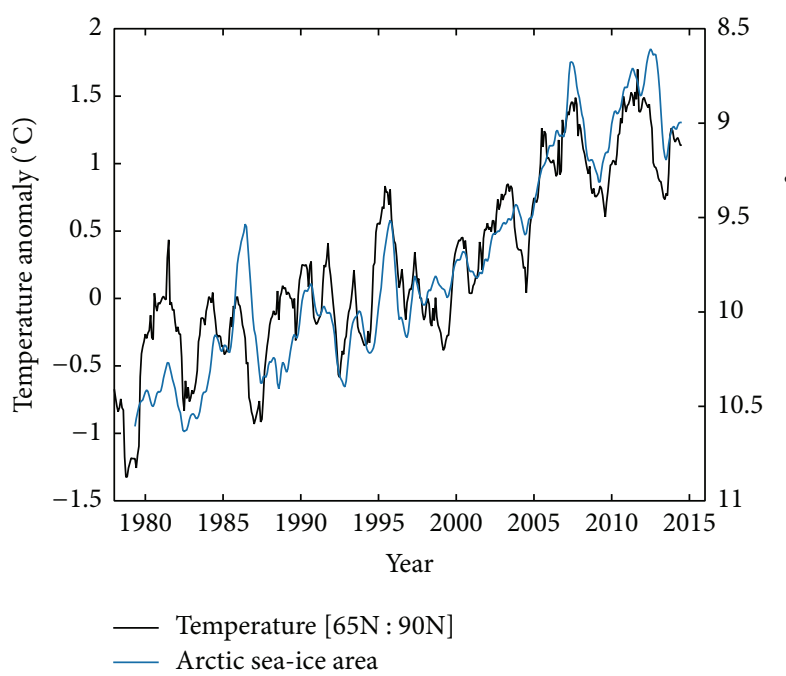

(a)

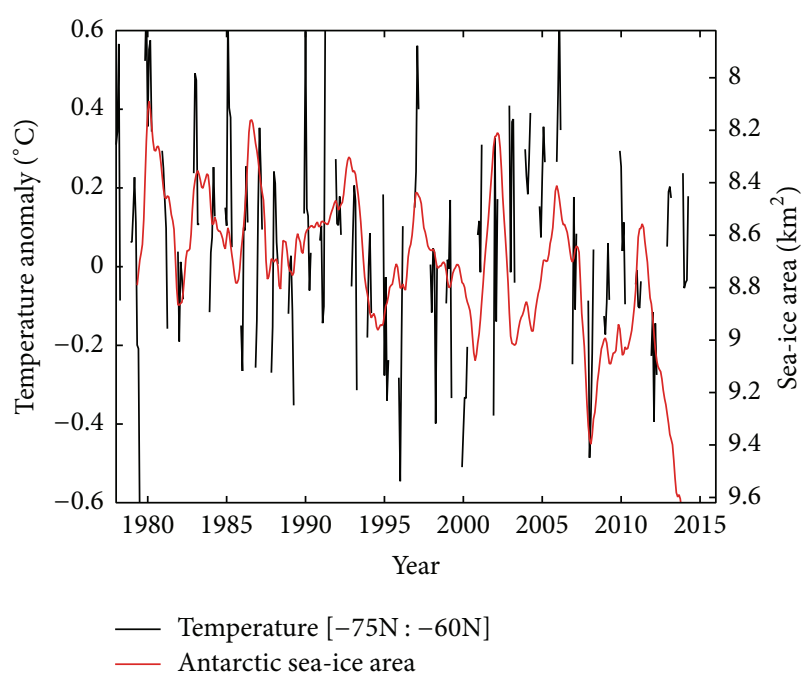

(b)

Figure 7: (a) The Arctic and (b) Antarctica. Comparison between the HadCRUT4 instrumental surface temperature and the sea-ice area. The temperature data are limited to the polar regions $65 \mathrm{~N}: 90 \mathrm{~N}$ for the Arctic and $-75 \mathrm{~N}:-60 \mathrm{~N}$ for the Antarctic.

averages of the monthly CMIP5 GCM scenario runs downloaded from Climate Explorer (http://climexp.knmi.nl). For the Arctic area we used the temperature anomaly surface (tas) simulations of 106 runs using the historical forcing functions before 2006 and the representative concentration pathways for the 2000-2100 irradiance increase between 4.5 and $8.5 \mathrm{~W} / \mathrm{m}^{2}$ (rcp-45 to rcp-85) scenarios after 2007 for latitude ranging from $65^{\circ} \mathrm{N}$ to $90^{\circ} \mathrm{N}$. For the Antarctic seaarea we used the same models to obtain the temperature surface anomaly for latitude ranging from $-60^{\circ} \mathrm{N}$ to $-75^{\circ} \mathrm{N}$.

Figures 9(a) and 9(b) show the CMIP5 GCM temperature predictions. Both for the Arctic and for the Antarctic sea regions, these computer simulations predict significant warming from 1978 to $2015:+5.5 \pm 0.03^{\circ} \mathrm{C}$ per century and $+2.0 \pm 0.01^{\circ} \mathrm{C}$ per century, respectively. However, while the predicted Arctic warming correlates with the observed Arctic warming and with the decrease of the Arctic seaice area during the period, the GCM predicted Antarctic warming is contradicted by the instrumental temperature records depicted in Figures 7(b) and 8(b) and by the observed increase of the Antarctic sea-ice area from 1978 to 2015. Figures 9(a) and 9(b) also demonstrate that the CMIP5 simulations fail to reproduce the 4-5-year oscillation observed in the depicted Arctic and Antarctic climatic records. 


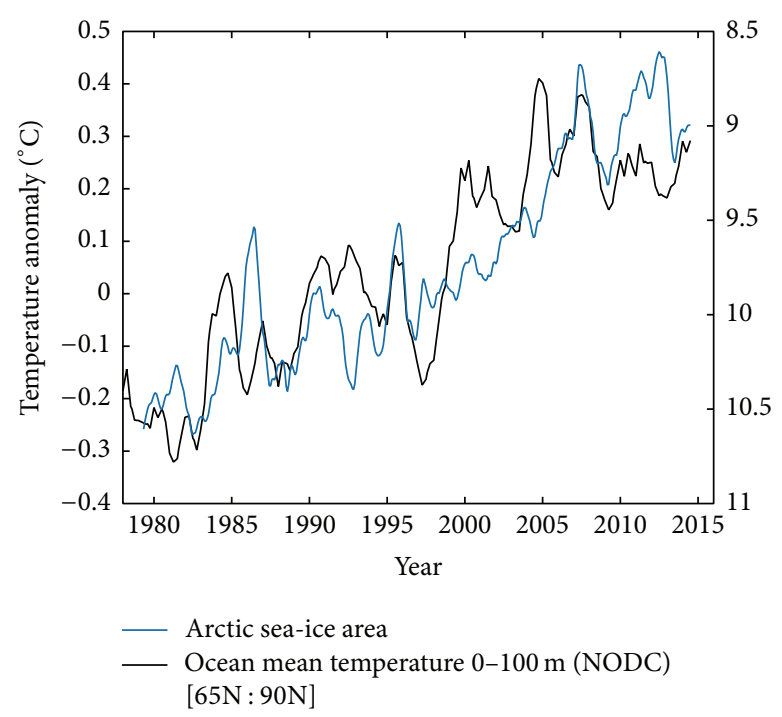

(a)

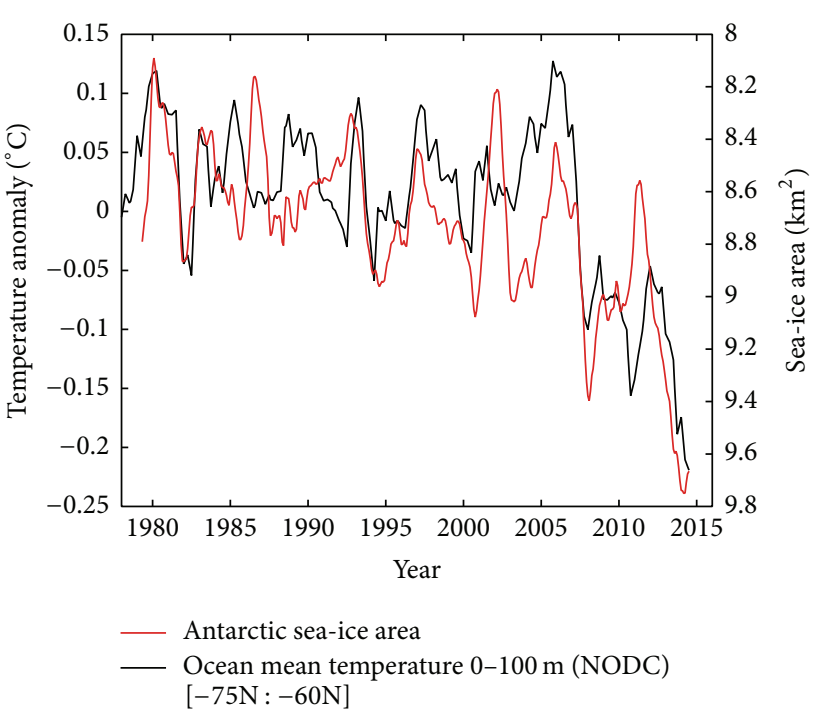

(b)

Figure 8: (a) The Arctic and (b) Antarctica. NODC ocean mean temperature (depth 0-100 m) temperature anomaly (black) versus the sea-ice area (color).

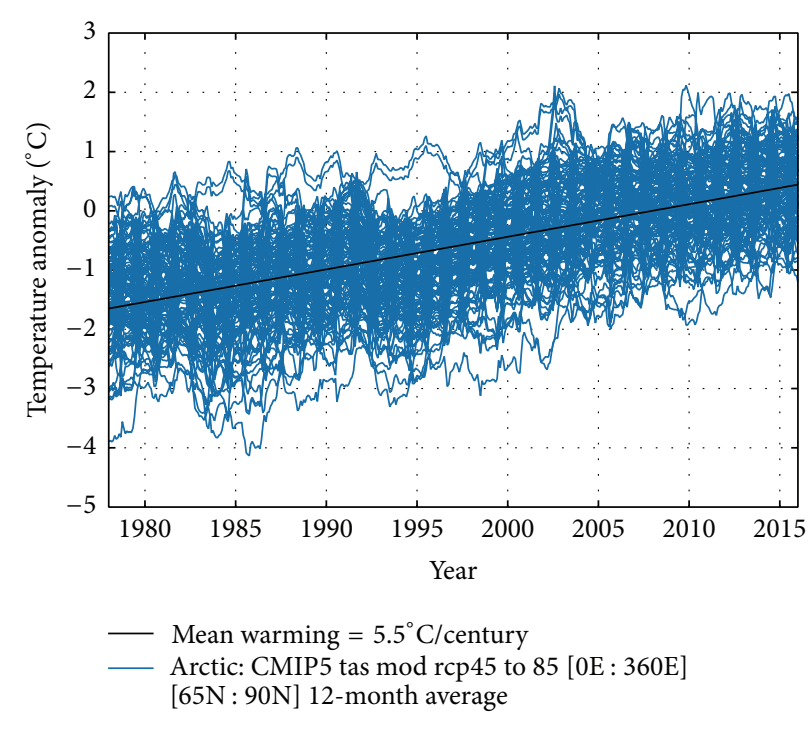

(a)

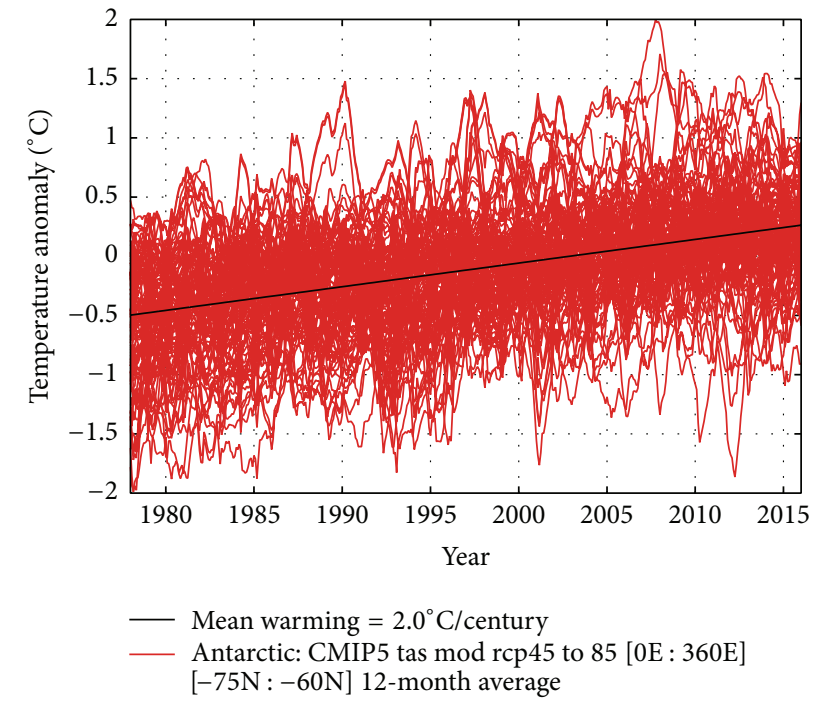

(b)

Figure 9: (a) The Arctic and (b) Antarctica. 106 CMIP5 simulations of the surface temperature anomaly (color) and of their mean trend (black).

\section{Discussion and Conclusions}

The Arctic and the Antarctica are characterized by an opposite climatic behavior in sea-ice area extensions. Since 1980 the Arctic sea-ice area has decreased while the Antarctic seaice area has increased. During the last 7 years the Arctic sea-ice area has stabilized as the global temperature did (cf. [15]), while the Antarctic sea-ice area has increased at a rate higher than during the previous decades (cf. Figure 3). In addition to the decadal trending, the Arctic and, in particular, the Antarctic sea-ice area also show consistent evidences for a 4-5-year oscillation both in the annually smoothed record and in the annual amplitude (Figures 5 and 6).

On the contrary, the CMIP5 GCMs have predicted significant warming of both the Arctic and the Antarctic seaice area (Figure 9). While the prediction could correlate with the observed reduction of the Arctic sea-ice area, the model prediction is clearly incompatible with the Antarctic data. The Antarctic sea-ice area has increased consistently during the last decades and in particular during the last 7 years indicating general cooling of the sea region surrounding the continent. The result is robust because it is fully confirmed 
by two alternative climatic temperature indices (see Figures 7 and 8). The CMIP5 GCMs also fail in reproducing the 45-year oscillation found in both the Arctic and the Antarctic sea-ice area records, which has been also found in the ENSO index [17].

Indeed, the CMIP5 general circulation models fail to reproduce numerous climatic patterns, in particular the natural oscillations $[15,18]$ that have been observed for centuries (cf. [19]). Natural oscillations can cause cooling or warming and, therefore, they contribute significantly to proper understanding of climatic changes. For example, concerning the temperature of the Arctic region, Chylek et al. [20] highlighted that about half of its last decades warming could have been related to the 60-year Atlantic Multidecadal Oscillation, that is, a temperature oscillation not reproduced by the CMIP5 general circulation models (cf. $[15,19])$.

Our results imply that the climate is regulated by natural mechanisms and natural oscillations that are not included yet in the climate models (cf. $[15,19])$. One possibility is that a proper cloud-albedo mechanism activated by solar and space weather magnetic phenomena could be missing in the models [21-25]. For example, magnetohydrodynamical processes in the Earth's core may cause magnetic field variations and thus Van Allen and atmospheric radiation/particle variation causing ionization and atmospheric impact on climate (cf. [26]). In fact, a significant correlation has been found between the global surface temperature and the global cloud cover index [15, Figure 19]. Essentially, if it is assumed that the global climate is partially modulated by the cloud cover change, then the cloud-albedo mechanism should effect differently the Arctic and the Antarctic regions. Less clouds in the Arctic decrease the albedo causing warming because the Arctic is made of ocean and its surface is usually darker relative to the cloud. However, in Antarctica less clouds could not change much the albedo given the fact that the surface is already mostly white. Thus, in Antarctica the greenhouse effect of the clouds should prevail, and less cloud should cause cooling.

Additional oceanic oscillation modes (e.g., Wind Stress, Global Sea Level, Atlantic Multidecadal Oscillation, AMO, North Atlantic Oscillation, NAO, Pacific Decadal Oscillation, PDO, and El-Niño Southern Oscillation, ENSO) could be involved in the process. Indeed, numerous climatic indices are correlated with each other and present a common 60year oscillation, although with different phases $[15,19,27]$. The short 37-year sea-ice records herein analyzed do not allow a detailed analysis of a 60-year oscillation. However, the records present an acceleration, which is more evident by change in their linear trend during the last decade, which agrees with a 60-year cyclical modulation.

The Arctic and Antarctic Oscillations (AO/AAO), which are commonly referred to as annular modes, should be particularly important for understanding the observed changes in the patterns in sea-ice area indices. There are two annular modes in Earth's atmosphere which are the most important patterns of climate variability in the Northern and Southern Hemisphere middle and high latitudes: a Northern Annular Mode (NAM) and a Southern Annular Mode (SAM). The annular modes can explain climatic variability at the weekly, monthly, annual, or decadal scales. For example, the NAM and SAM explain about $20-30 \%$ of the total variance in the geopotential height and wind fields (cf. [2830]). The annular modes regulate the ocean and atmospheric circulation but they are also regulated by feedbacks between the induced changes in the zonal wind and the wave fluxes (http://www.atmos.colostate.edu/ davet/ao/introduction .html). Thus, the changes in the ocean and atmospheric circulation can be driven by the cloud feedback activated by space weather changes as discussed above.

\section{Conflict of Interests}

The authors declare that there is no conflict of interests regarding the publication of this paper.

\section{References}

[1] W. F. Weeks, On Sea Ice, University of Alaska Press, 2010.

[2] S. Lee, "A theory for polar amplification from a general circulation perspective," Asia-Pacific Journal of Atmospheric Sciences, vol. 50, no. 1, pp. 31-43, 2014.

[3] R. T. Pierrehumbert, Principles of Planetary Climate, Cambridge University Press, 2010.

[4] National Aeronautics and Space Administration and Jet Propulsion Laboratory, NASA Study Finds Rapid Changes in Earth's Polar Ice Sheets, National Aeronautics and Space Administration, Jet Propulsion Laboratory, 2002, http://quest.arc.nasa.gov/ news/space/2002/08-30a.txt.

[5] R. B. Alley, P. U. Clark, P. Huybrechts, and I. Joughin, "Ice-sheet and sea-level changes," Science, vol. 310, no. 5747, pp. 456-460, 2005.

[6] J. L. Bamber, R. E. M. Riva, B. L. A. Vermeersen, and A. M. Lebrocq, "Reassessment of the potential sea-level rise from a collapse of the West Antarctic Ice Sheet," Science, vol. 324, no. 5929, pp. 901-903, 2009.

[7] M. Studinger, "Geologic Contral on Fast Ice Flow-West Antarctic Ice Sheet," Lamont-Doherty Earth Observatory, http:// www.ldeo.columbia.edu/ mstuding/wais.html.

[8] F. Fetterer, K. Knowles, W. Meier, and M. Savoie, Sea Ice Index, National Snow and Ice Data Center, Boulder, Colo, USA, 2002.

[9] D. Strain, "Collapsing coastlines: how Arctic shores are pulled a-sea," Science News, vol. 180, no. 2, pp. 18-21, 2011.

[10] I. Peterson, "Mathematician on ice: adventurous voyages to Antarctica test mathematical models of sea ice," Science News, vol. 158, no. 7, pp. 106-108, 2000.

[11] R. Monastersky, "Sea change in the arctic: an oceanful of clues points to climatic warming in the far north," Science News, vol. 155, pp. 104-106, 2009.

[12] A. J. Cook, A. J. Fox, D. G. Vaughan, and J. G. Ferrigno, "Retreating glacier fronts on the Antarctic Peninsula over the past half-century," Science, vol. 308, no. 5721, pp. 541-544, 2005.

[13] P. T. Doran, J. C. Priscu, W. Berry Lyons et al., "Antarctic climate cooling and terrestrial ecosystem response," Nature, vol. 415, no. 6871, pp. 517-520, 2002.

[14] Intergovernmental Panel on Climate Change (IPCC), Fifth Assessment Report (AR5), Intergovernmental Panel on Climate Change (IPCC), 2013.

[15] N. Scafetta, "Discussion on climate oscillations: CMIP5 general circulation models versus a semi-empirical harmonic model 
based on astronomical cycles," Earth-Science Reviews, vol. 126, pp. 321-357, 2013.

[16] C. P. Morice, J. J. Kennedy, N. A. Rayner, and P. D. Jones, “Quantifying uncertainties in global and regional temperature change using an ensemble of observational estimates: the HadCRUT4 data set," Journal of Geophysical Research: Atmospheres, vol. 117, no. 8, Article ID D08101, 2012.

[17] A. Mazzarella, A. Giuliacci, and I. Liritzis, "On the 60-month cycle of multivariate ENSO index," Theoretical and Applied Climatology, vol. 100, no. 1, pp. 23-27, 2010.

[18] N. Scafetta, "Testing an astronomically based decadal-scale empirical harmonic climate model versus the IPCC (2007) general circulation climate models," Journal of Atmospheric and Solar-Terrestrial Physics, vol. 80, pp. 124-137, 2012.

[19] N. Scafetta, "Multi-scale dynamical analysis (MSDA) of sea level records versus PDO, AMO, and NAO indexes," Climate Dynamics, vol. 43, no. 1-2, pp. 175-192, 2014.

[20] P. Chylek, N. Hengartner, G. Lesins et al., "Isolating the anthropogenic component of Arctic warming," Geophysical Research Letters, vol. 41, no. 10, pp. 3569-3576, 2014.

[21] J. Kirkby, "Cosmic rays and climate," Surveys in Geophysics, vol. 28, no. 5-6, pp. 333-375, 2007.

[22] N. Scafetta, "Empirical evidence for a celestial origin of the climate oscillations and its implications," Journal of Atmospheric and Solar-Terrestrial Physics, vol. 72, no. 13, pp. 951-970, 2010.

[23] N. Scafetta, "Discussion on the spectral coherence between planetary, solar and climate oscillations: a reply to some critiques," Astrophysics and Space Science, vol. 354, no. 2, pp. 275299, 2014.

[24] H. Svensmark, "Cosmoclimatology: a new theory emerges," Astronomy and Geophysics, vol. 48, no. 1, pp. 18-24, 2007.

[25] B. A. Tinsley, "The global atmospheric electric circuit and its effects on cloud microphysics," Reports on Progress in Physics, vol. 71, no. 6, Article ID 066801, 2008.

[26] I. Liritzis and E. Grigori, "Astronomical forcing in cosmogenic Be-10 variation from east Antarctica coast?" Journal of Coastal Research, vol. 14, no. 3, pp. 1065-1073, 1998.

[27] M. G. Wyatt and J. A. Curry, "Role for Eurasian Arctic shelf sea ice in a secularly varying hemispheric climate signal during the 20th century," Climate Dynamics, vol. 42, no. 9-10, pp. 27632782, 2014.

[28] J. Pedlosky, Geophysical Fluid Dynamics, Springer, 2nd edition, 1987.

[29] P. B. Rhines, "Waves and turbulence on a beta-plane," Journal of Fluid Mechanics, vol. 69, no. 3, pp. 417-443, 1975.

[30] D. W. J. Thompson and J. M. Wallace, "Annular modes in the extratropical circulation. Part I: month-to-month variability," Journal of Climate, vol. 13, no. 5, pp. 1000-1016, 2000. 

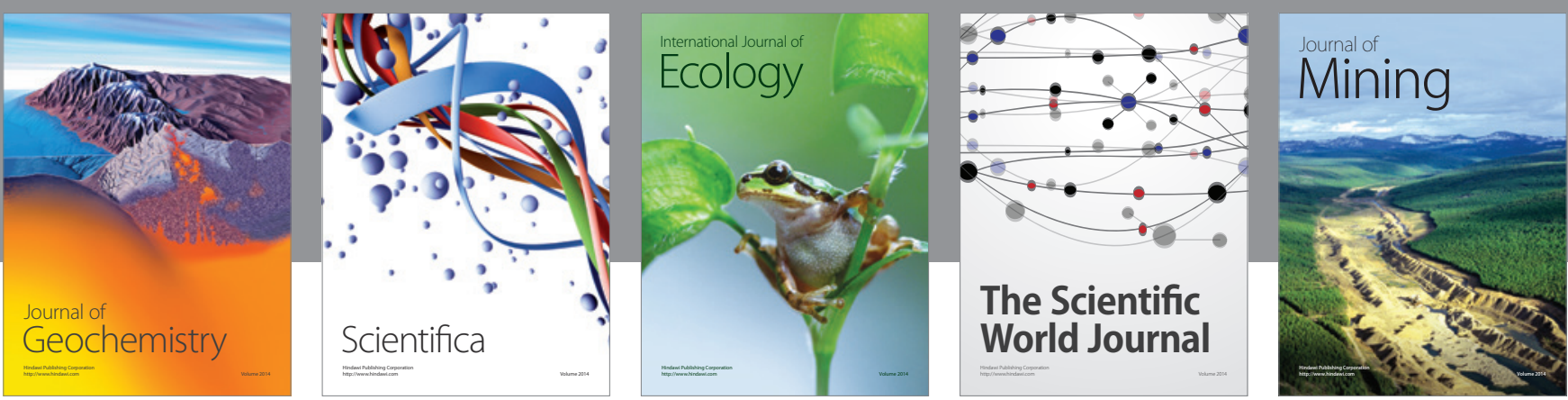

The Scientific World Journal
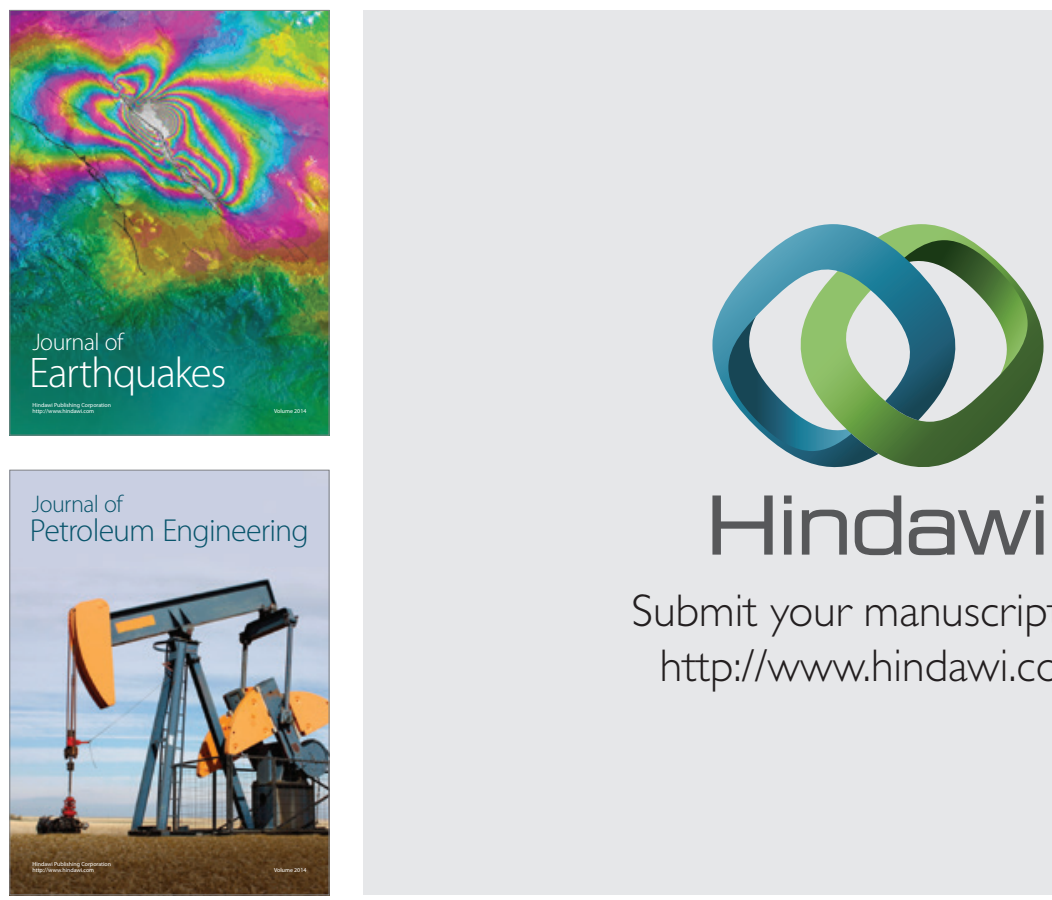

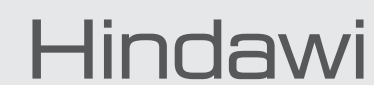

Submit your manuscripts at

http://www.hindawi.com
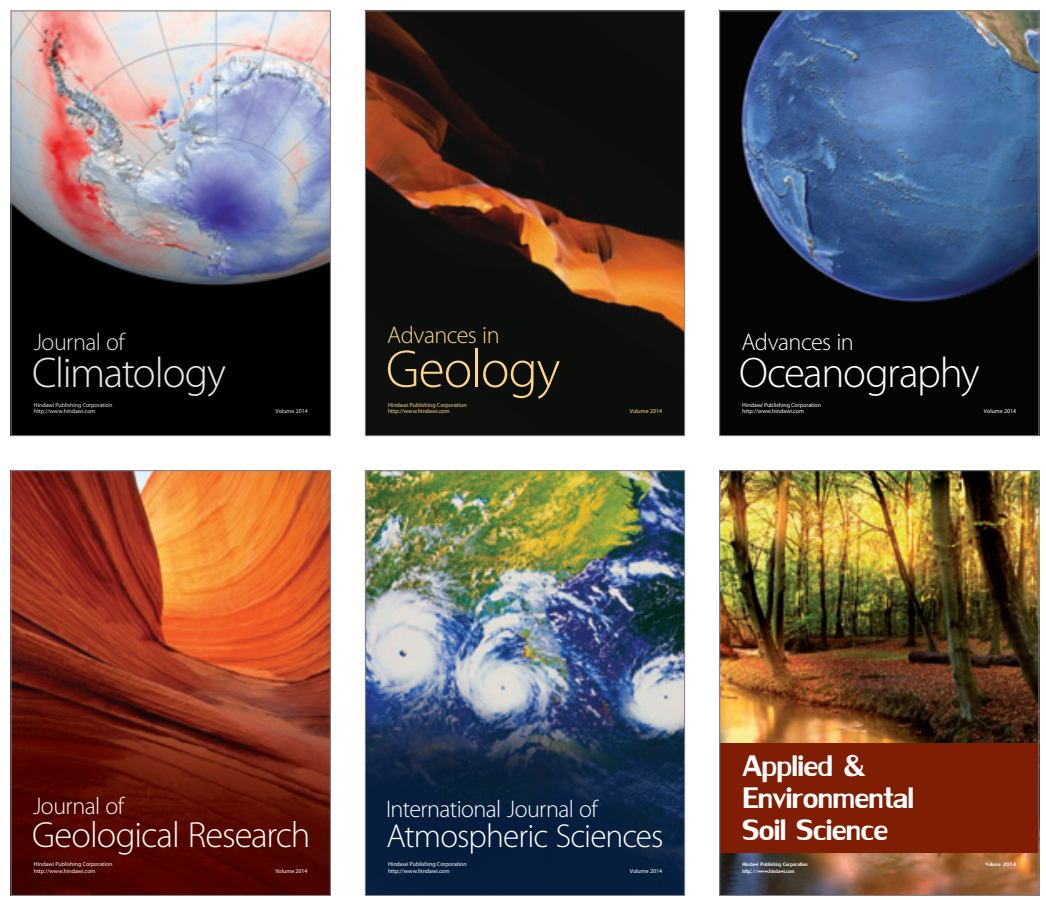
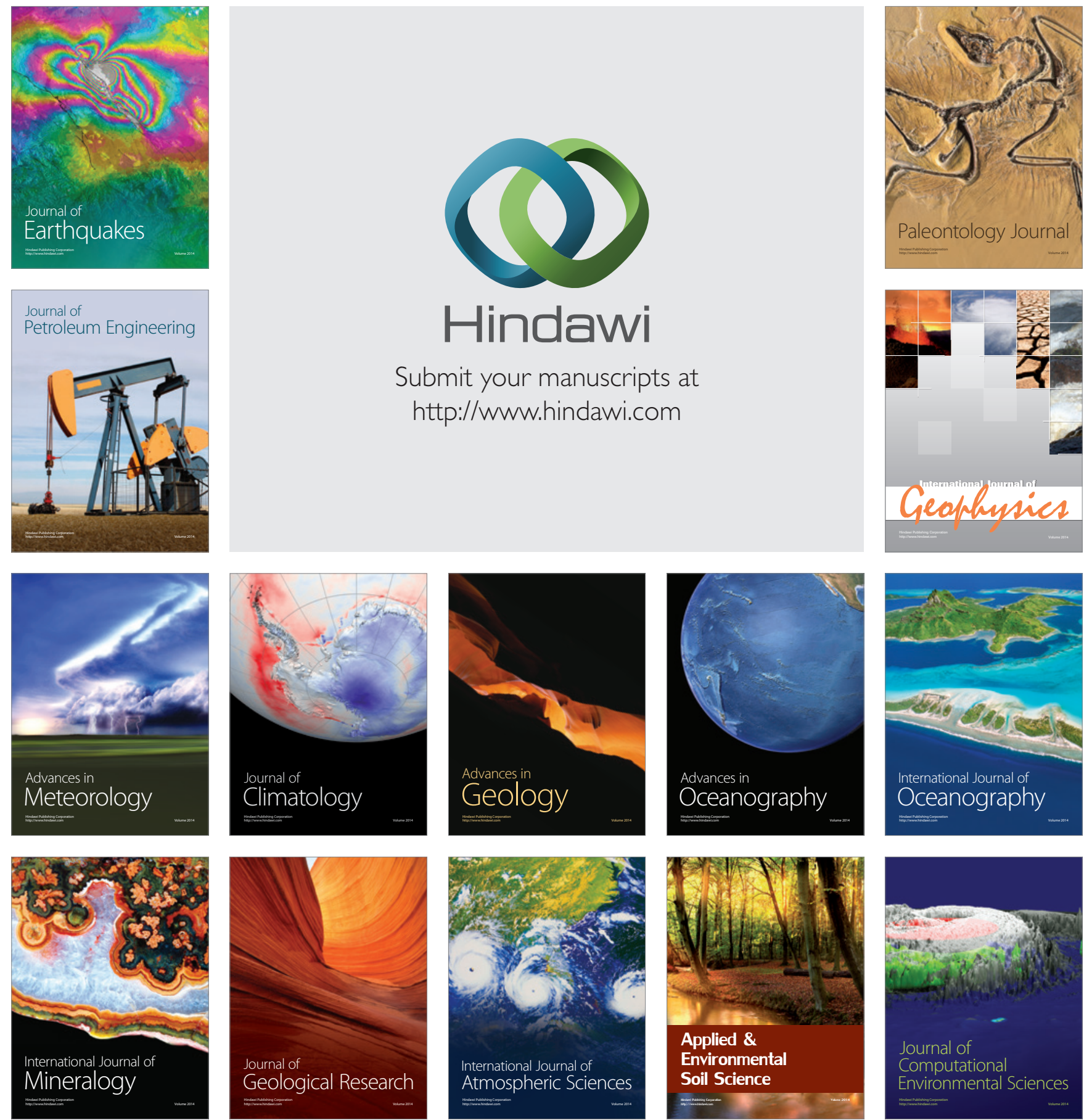